\title{
EXPERIÊNCIAS PEDAGÓGICAS PARA INSERÇÃO DO PESCADO NA ALIMENTAÇÃO ESCOLAR
}

BEZERRA, H.C.B.S. ${ }^{1}$; SILVA, V.M. ${ }^{2}$; PIRES, C.R.F. ${ }^{3}$; SANTOS, V.F. ${ }^{4}$; SOUSA, D.N. ${ }^{5}$ \& KATO, H.C.A.

${ }^{1}$ Graduada pela Universidade Federal do Tocantins (UFT). E-mail: cristinebsbezerra@ gmail.com; ${ }^{2}$ Graduada pela UFT. E-mail:

vanessanutricao94@gmail.com; ${ }^{3}$ Professora da UFT. E-mail: carolinerfpires@ mail.uft.edu.br; ${ }^{4}$ Mestranda pela UFT. E-mail:

vivianefsnutri@gmail.com, ${ }^{5}$ Analista da Embrapa Pesca e Aquicultura. E-mail: diego.sousa@embrapa.br; Pesquisadora da Embrapa Pesca e Aquicultura. E-mail: hellen.almeida@embrapa.br

Artigo submetido em março de 2020 - DOI 10.32356/exta.v20.n2.43638

\section{RESUMO}

Este estudo é um relato de experiência, retratado a partir da perspectiva da Educação Alimentar e Nutricional (EAN), para inserção do pescado na alimentação escolar. O trabalho tem o objetivo de relatar as metodologias utilizadas no processo de intervenção nutricional para incentivo ao consumo do pescado envolvendo alunos de uma escola pública de Palmas, Tocantins. Para o desenvolvimento das ações pedagógicas utilizou-se de metodologias lúdicas como: peça teatral, oficina culinária e jogo dos sete erros. A avaliação do conhecimento foi obtida pela aplicação do questionário pré e pós testes. Observou-se a evolução dos escolares com o aumento de acertos após a intervenção extensionista ao permitir com que tenham condições de refletir e tomar decisões mais conscientes sobre terem (ou não) uma alimentação nutricionalmente saudável. Portanto, as ações de EAN foram consideradas ferramentas pedagógicas importantes para potencializar o ensino-aprendizado dos escolares, podendo ser replicadas em experiências semelhantes, com público de mesmas características.

PALAVRAS-CHAVE: Educação Alimentar e Nutricional. Promoção da Saúde. Consumo de Pescado.

\section{PEDAGOGICAL EXPERIENCES FOR INSERTING FISH IN SCHOOL FOOD}

\begin{abstract}
This study is an experience report, portrayed from the perspective of Food and Nutrition Education (EAN), for the insertion of fish in school meals. The work aims to report the methodologies used in the nutritional intervention process to encourage the consumption of fish involving students from a public school in Palmas, Tocantins. For the development of pedagogical actions, playful methodologies were used, such as: theater play, culinary workshop and the game of seven errors. Knowledge assessment was
\end{abstract}

obtained by applying pre and post tests. The evolution of the students was observed with the increase of correct answers after the extension intervention, allowing them to be able to reflect and make more conscious decisions about having (or not) a nutritionally healthy diet. Therefore, the EAN actions were considered important pedagogical tools to enhance the teaching-learning of students, and can be replicated in similar experiences, with the same characteristics.

KEYWORDS: Food and Nutrition Education. Health Promotion. Fish Consumption.

\section{INTRODUÇÃO}

Com o intuito de proporcionar alimentação baseada nas recomendações nutricionais e, dessa maneira, aumentar a aceitabilidade de alguns alimentos saudáveis, torna-se interessante a adoção de ações metodológicas de Educação Alimentar e Nutricional (EAN) no ambiente escolar, visto que, desde a primeira infância, são iniciados os costumes alimentares, que refletirão ao longo da vida (BRASIL, 2006). 
Para a condução das atividades de EAN foram adotadas atividades lúdicas que se destacam no incentivo à aprendizagem, ao promover a construção de novos conhecimentos, e ao colaborar para o desenvolvimento cognitivo dos escolares. Torna-se, assim, uma ferramenta de ensino e aprendizagem prazerosa, estimulante e de relevância para se atingir o propósito esperado, podendo ser conduzida em forma de jogos, teatro, música, brincadeiras, oficinas dentre outras ações lúdicas (SANTOS et al, 2019; PIRES et al, 2020).

O presente estudo teve como objetivo relatar as propostas metodológicas utilizadas no processo de intervenção para incentivo ao consumo do pescado em uma escola pública de Palmas (TO), utilizando atividades lúdicas voltadas à Educação Alimentar e Nutricional.

O consumo de pescado ${ }^{1}$ é considerado mais saudável quando comparado com os outros tipos de carnes, já que seu perfil proteico supera em valor biológico outras fontes de origem animal, como a carne bovina e o leite (SANTOS et al, 2019). Por isso que justifica a importância de se realizar ações de intervenção em EAN para o incentivo do pescado na alimentação.

\section{MATERIAIS E MÉTODOS}

As atividades de EAN foram desenvolvidas com 27 escolares, cursando o $5^{\circ}$ ano do ensino fundamental em uma escola localizada em Palmas, estado do Tocantins.

O procedimento metodológico de caráter quali-quantitativo relatado neste trabalho foi agrupado em quatro momentos distintos orientados pela abordagem de Freire (2011) e na aplicação de questionário pré e pós as intervenções nutricionais (ANDRADE et al., 2016). Os dados coletados foram computados em planilha de excel.

Para a proposição das atividades de EAN na supracitada escola foi necessária previamente a realização de reunião com a diretora da escola e o professor regente da turma selecionada para execução do projeto, com o intuito de explicar as ações que seriam desenvolvidas com os discentes, e como eles poderiam contribuir para a consecução desta atividade.

\footnotetext{
${ }^{1} \mathrm{O}$ consumo mundial de pescado cresceu 5\% ao ano no período de 1961 a 2018. Isto equivale a um acréscimo de 20,3 para 20,5 kg/habitante/ano. Enquanto o Brasil, em 2018, atingiu a média de 14,9 kg/habitante/ano, índice bem inferior ao consumo mundial (FAO, 2018). Isto justifica a necessidade de intervenções para o aumento do consumo do pescado considerando seus importantes atributos nutricionais para a saúde humana.
} 
No segundo momento foi aplicado o pré-teste contendo oito questões com respostas fechadas, com o intuito de avaliar o conhecimento prévio dos escolares a respeito dos nutrientes presentes no peixe e, ainda, relacioná-los aos benefícios (ou não) para a saúde.

Esta etapa foi conduzida através de uma apresentação teatral. A peça ${ }^{2}$ de teatro foi adaptada com personagens da "Turma da Mônica", com foco nas consequências de uma má alimentação e a incidência de agravos à saúde. Foram abordadas também informações nutricionais do pescado e a importância de seu consumo. Para concluir a divulgação do conteúdo proposto, foram utilizados cartazes coloridos e ilustrativos contendo os minerais, vitaminas e macronutrientes presentes no peixe e, assim, foi explicado a função e os benefícios dos mesmos para o organismo humano.

No terceiro momento consistiu na realização de oficina culinária com o tema: "Sanduíche nutritivo". No início, foram distribuídas toucas e realizado a higienização das mãos das crianças que se posicionaram ao redor da mesa, onde estavam os ingredientes devidamente cortados e separados, para que todas participassem na montagem do alimento.

Em seguida, os facilitadores do processo apresentaram cada alimento que estava sobre a mesa, sendo eles o pão de forma, a alface, a cenoura crua ralada e o patê de atum. Apesar de não constituir um peixe comercializado pela agricultura familiar, tampouco relevante para a cultura alimentar tocantinense, utilizou-se o atum pela praticidade e valor reduzido para a aquisição, já que a metodologia empregada visava a conscientização acerca de parâmetros nutricionais relevantes do peixe enquanto grupo alimentar. Logo adiante foi dado o comando para que cada aluno montasse o seu sanduíche. Isto reforçou com que as crianças tivessem como referencial desses alimentos uma alimentação saudável.

$\mathrm{Na}$ última etapa foi entregue a cada escolar um folder, contendo duas receitas: uma do sanduíche nutritivo de peixe e outra de torta de atum. Neste documento também constava um jogo dos sete erros da Turma da Mônica, com intuito de despertar a atenção, a agilidade e a percepção das crianças sobre os diferentes tipos de alimentos e suas funções.

Para encerrar as atividades pedagógicas, os alunos receberam as fichas contendo o pós-teste com as mesmas questões respondidas no pré-teste, com a finalidade de analisar qualitativamente e comparativamente qual foi o grau de aprendizagem das crianças após a

\footnotetext{
${ }^{2} \mathrm{O}$ roteiro da peça teatral pode ser encontrado no estudo de Pires et al. (2020).
} 
intervenção extensionista.

\section{RESULTADOS ${ }^{3}$ E DISCUSSÕES}

Das propostas metodológicas relatadas acima, participaram 27 crianças do $5^{\circ}$ ano do ensino fundamental de ambos os sexos, sendo 14 (51,8\%) do sexo feminino e $13(48,14 \%)$ do sexo masculino, com idade entre 10 a 11 anos.

Quando questionados se gostavam de peixe, $11 \%$ dos escolares afirmaram não gostar, o que pode estar relacionado a ausência de hábito ao consumir o alimento, pois não é um produto de preparação fácil, e a população está acostumada com praticidade. Ainda, pode estar relacionado ao fato deste produto possuir gargalos na sua distribuição e comercialização, o que impede aumentar a oferta (BONACINA; QUEIROZ, 2007).

Ribeiro et al. (2018), analisando o comportamento do consumo de pescado em Palmas (TO), detectaram que o consumo no município ainda era relativamente baixo, com apenas $21,16 \%$ dos entrevistados mantendo-se dentro da média de consumo recomendada pela Organização das Nações Unidas para Alimentação e Agricultura - FAO, mesmo tratando-se de uma região com características favoráveis para o desenvolvimento da piscicultura, e com atividade de pesca frequente (FAO, 2018). Os autores destacam que este fato está ligado a fatores socioeconômicos, sendo o preço o principal entrave para a maior presença do pescado na mesa das famílias palmenses.

Por outro lado, $89 \%$ dos escolares afirmaram gostar de peixe, destes consumidores $52 \%$ apontaram a preferência por consumir peixe frito e $44 \%$ peixe ao molho. Na literatura, alguns autores apontam que as crianças podem ser influenciadas em casa a consumir determinados alimentos, visto que os pais desempenham o papel de referência e de primeiros educadores nutricionais e, como consequência, influenciam diretamente o comportamento alimentar dos filhos (SANTOS et al., 2019; TEIXEIRA et al., 2020). A maioria (96\%) dos escolares afirmou que o peixe é um alimento importante para a saúde. Estudos epidemiológicos apontam que a ingestão elevada de peixe contribui significativamente para a diminuição da mortalidade e morbidade cardiovascular, ao demonstrar resultados positivos no metabolismo das lipoproteínas em atividades das plaquetas e de coagulação, função endotelial

\footnotetext{
${ }^{3}$ Outros resultados sobre as práticas pedagógicas em EAN realizadas ver o estudo de Pires et al. (2020).
} 
e rigidez arterial (SCHERR et al., 2014).

Essas circunstâncias motivaram a ação extensionista voltada à promoção da EAN, através da realização de teatro para as crianças, com o intuito de promover aprendizado sobre a composição nutricional, demonstrando o quanto é importante consumir peixe, e que é possível incluí-lo em outras refeições, através de distintas preparações.

O teatro contribui para o desenvolvimento humano, pois estimula os sentidos, levando ao prazer de aprender. Possibilita, ainda, maior interação sobre o contexto a ser aprendido com o mundo em torno das crianças, ajudando-as a reduzir a timidez, desenvolvendo a criatividade, possibilitando maior memorização do conteúdo assistido, cabendo aos facilitadores problematizar essa aprendizagem (SANTOS; SANTOS, 2012).

Em relação aos demais questionamentos, ao comparar as respostas de caráter relacionado à avaliação do conteúdo apresentado do pré e pós teste, houve acréscimo no número de acertos no pós-teste, demonstrando que a ação extensionista realizada com os alunos teve impacto positivo na percepção dos conteúdos que foram transmitidos a eles.

No estudo de Silva et al. (2018), que também realizaram atividades de EAN com alunos desta mesma escola, mas utilizando outras metodologias lúdicas, tal como o uso de paródias de canções infantis correlacionadas com a temática pescado, também constataram na comparação dos questionários pré e pós-teste, resultados satisfatórios.

Andrade et al. (2016) fez o uso do pré e pós-teste para avaliar o conhecimento que os alunos tinham sobre Bioquímica Clínica II, e ver se foi consolidado a aprendizagem dos temas abordados. Utilizando o pré-teste obtiveram aproveitamento de $56,15 \%$ nas questões e no pósteste perceberam que teve média em torno de $67,7 \%$, verificando, assim, melhora das repostas após a intervenção.

No geral para as questões que no pré teste apresentaram mais de $50 \%$ de erros, a intervenção pedagógica resultou em um incremento que variou de 29,5 a 40,8\% de acertos. Quando os alunos foram solicitados para assinalar quais os nutrientes estavam presentes no peixe, observou-se que, no pré-teste e pós-teste houve $100 \%$ de acertos para proteína, já o ômega-3 no pré-teste, $44,5 \%$ assinalaram corretamente a questão, e no pós-teste aumentou o número de acertos para $74 \%$. Sobre as vitaminas A e D foram registrados acertos no pré-teste em apenas 15,62\% dos respondentes, sendo que após a intervenção extensionista o percentual de acertos no pós-teste foi para 53,12\%. Isso indica a importância de um processo educacional 
contínuo para maior aprendizagem dos conteúdos referentes à alimentação e nutrição.

Os escolares não escolheram a alternativa que continha a opção de açúcar, obtendo então $100 \%$ de acerto. Com relação ao cálcio, o percentual de acertos evoluiu consideravelmente de $48,1 \%$ no pré-teste para $88,9 \%$ no pós-teste. Sobre os conservantes, $7,4 \%$ dos alunos assinalaram que o mesmo está presente no peixe, embora após a encenação do teatro esse percentual passou para $100 \%$ de acerto. Dessa forma, o teatro como ferramenta pedagógica possibilita a produção do conhecimento, ao ponto de tornar o processo de ensino e aprendizagem transformador e libertador (NILES; SOCHA, 2015).

Ao observar as respostas para o micronutriente cálcio, 85,15\% dos alunos fizeram associação correta no pré-teste e $92,59 \%$ no pós-teste, indicando que a maior parte dos escolares conseguiram identificar o benefício à saúde causado pela ingestão deste mineral.

O cálcio é o mineral mais encontrado no corpo humano, estando presente em ossos e dentes, tornando-os responsáveis pela manutenção dos níveis de cálcio sérico. Pode ser encontrado no leite e seus derivados, também está presente na carne de peixe, como sardinha, nas verduras e folhosos verde escuros (FRANÇA; MARTINI, 2014).

Neste contexto, sugere-se que as crianças devam ter consumo adequado de cálcio durante a infância, pois na fase adulta a sua perda é diária. A falta desse mineral pode causar problemas no processo de crescimento, desmineralização dos ossos causando osteoporose, disfunções na divisão celular, falhas durante a contração muscular, complicações na coagulação sanguínea e secreção hormonal (FRANÇA; MATINI, 2014).

A proteína proveniente do pescado apresenta qualidade superior quando comparada às proteínas encontradas nas carnes bovina, suínas e de aves, por possuir teor menor de tecido conjuntivo. Além disso, é de fácil digestão e rica em metionina e lisina, aminoácidos essenciais, não sendo estes produzidos pelo organismo humano. Sendo assim, a ausência desses nutrientes pode causar deterioração proteica, atingindo o tecido muscular e impactando no crescimento infantil (LATORRES, 2014).

Quanto à pergunta referente à patologia relacionada à ausência de ferro, houve 70,37\% de acertos no pré-teste e $81,48 \%$ no pós-teste, indicando também efeito positivo decorrente da intervenção e, por consequência, ter aumentado o número de questões corretas.

A população em situação de vulnerabilidade no país apresenta índice elevado de anemia, que pode ser resultado das carências nutricionais como ferro, ácido fólico e vitamina 
B12, sendo essa deficiência associada a diversos fatores, tais como: alimentação inadequada, doenças infecciosas, baixo peso ao nascer, má-absorção de nutrientes e nascimentos prematuros (PEREIRA et al., 2007).

Segundo Carvalho (2006), a deficiência de ferro causa problemas no crescimento, distúrbios comportamentais, fadiga e disfunções neurológicas o que pode afetar no desenvolvimento escolar.

Em relação ao questionamento sobre a função do ômega-3, no pré-teste os escolares tiveram 40,74\% de acertos, sendo que após a intervenção este número elevou-se para 96,27\%. É sabido que os peixes possuem significativas quantidades de ácidos graxos poli-insaturados, destacando o eicosapentanóico (EPA) e o docosaexaenoico (DHA) da série ômega-3, possuindo funções na redução do colesterol sérico, prevenindo doenças cardiovasculares e outras patologias como: dermatite atópica, lúpus, psoríase, artrite reumática, esclerose múltipla, diabetes mellitus, colite ulcerativa e câncer (MARTINS, 2008).

Ceccon et al. (2012) desenvolveram um estudo com crianças de 3 a 5 anos, que teve como objetivo analisar a prática de hábitos alimentares saudáveis e o uso de atividades lúdicas, pelos quais obtiveram resultados semelhantes. Foi observado que as crianças no préteste não tinham conhecimento sobre hábitos alimentares saudáveis, já no pós-teste houve melhorias significativas no entendimento sobre esses alimentos, e sua importância para uma boa saúde. Com isso, constata-se que as intervenções nutricionais estimulam as crianças a terem aprendizagem sobre os alimentos saudáveis, sendo essas ações eficientes ferramentas pedagógicas para a EAN nas escolas.

Segundo Lanes et al. (2012), as atividades lúdicas são fundamentais para despertar nas crianças hábitos saudáveis. Assim, esta metodologia permite também participação interativa e ativa dos indivíduos durante as intervenções extensionistas, lhes concedendo certa liberdade e criticidade nas escolhas alimentares.

Para o presente estudo utilizou-se de outra metodologia lúdica, a oficina culinária, intitulada "Sanduíche Nutritivo". As atividades de oficina culinária vão além do incentivo aos bons hábitos alimentares, pois a partir dela podem-se desenvolver outros saberes, como a compreensões a respeito da higiene pessoal, matemática ao envolver as medidas dos ingredientes, a habilidade de leitura e interpretação ao proferir e executar as receitas práticas, dentre outras possíveis relações interdisciplinares. Neste tipo de oficina os escolares podem 
aguçar os sentidos como: visão, tato, olfato e paladar, pois o contato e a manipulação do produto lhes permitem isso. Essa participação no preparo dos alimentos induz o aumento do interesse pelo produto, pois manipular, estar envolvido no preparo e degustar os alimentos pode estimular seu consumo (SILVA et al. 2010).

Figueiredo et al. (2010), afirmam que desenvolver oficinas culinárias relacionadas com EAN pode-se modificar a realidade do público-alvo, atingindo gradativamente resultados positivos no campo da saúde pela influência do processo educacional, pressupondo que na fase escolar as crianças são mais receptivas a novos saberes, levando-as também para o ambiente familiar.

Para finalizar as intervenções extensionistas, foi entregue aos escolares um folder contendo receitas à base de peixe para prepararem em casa, com a intenção de que as crianças levem as informações adquiridas para o ambiente familiar, e também para que consumam o produto novamente juntos aos pais, reforçando a atividade prática. Neste sentido, os autores Ramos e Stein (2000) consideram que o hábito alimentar consiste na repetição de ações, o que leva, no caso das crianças, a adquirirem novos costumes.

As receitas foram acompanhadas de jogos educativos para reforçar o conteúdo repassado durante a ação de EAN no ambiente escolar. Isso porque, conforme preconizado por Kiya e Dionizio (2014), as atividades lúdicas e os jogos educativos são estratégias de ensino que contribuem para que os alunos tenham maior interesse pelo que vai ser ensinado, melhorando o desempenho escolar e, ainda, percebem que eles adquirem maior facilidade para aprender determinado assunto. Isso permite com que as crianças tenham a sensação de liberdade para explorar e experimentar, descobertas induzidas pela curiosidade (OLIVEIRA; DIAS, 2017).

\section{CONCLUSÃO}

Em curto prazo não se pode presumir que as ações extensionistas com foco na EAN provocaram sólida melhoria nos hábitos alimentares dos escolares, por meio do incentivo ao consumo de pescado. Entretanto, foi construída junto com as crianças partícipes deste processo uma base de conhecimento a respeito dos nutrientes presentes no pescado, como pode ser observado nas tabelas dos resultados, o que permitiu com que os escolares tenham condições de refletir e tomar decisões mais conscientes sobre terem (ou não) uma alimentação nutricionalmente saudável. 
Por esse motivo, as atividades de EAN são importantes para o ensino aprendizado deste público, pois estimulam os escolares a criarem hábitos saudáveis, visando à alimentação balanceada e equilibrada, bem como incentivando o consumo de alimentos que antes não eram consumidos (ou não tidos como saudáveis).

Sugere-se que as ações de EAN devem ocorrer de forma contínua no ambiente escolar, permitindo que os estudantes tenham senso crítico e sejam conscientes sobre escolhas alimentares adequadas a sua faixa etária, consolidando assim base de conhecimento a respeito dos nutrientes e benefícios à saúde humana.

Portanto, atividades lúdicas facilitam o entendimento das crianças, proporcionando maior interação entre elas e os executores, estimulando com que o conteúdo abordado seja levado também para o ambiente familiar, ao ser compartilhado o conhecimento adquirido com os responsáveis.

\section{REFERENCIAS}

ANDRADE, E. D. L; LUZ, A. B. A; OLIVEIRA, A. A. G; RICARTE, L. P; MENESES, R. R. C; QUEIROZ, M. G. R. Uso de questionários pré-teste e pós-teste: uma ferramenta de ensino e aprendizagem na disciplina de bioquímica clínica II. Anais do Encontro de Iniciação à Docência, Fortaleza, 25. Fortaleza: UFCE, 2016.

BRASIL. Ministério da Saúde e Ministério da Educação e Cultura. Portaria $n^{\circ}$ 1.010/2006. Diretrizes para a promoção da alimentação saudável nas escolas de educação infantil, fundamental e nível médio das redes públicas e privadas, em âmbito nacional. Diário Oficial da União, s/p, 2006.

BONACINA, M; QUEIROZ, M. I. Elaboração de empanado a partir da corvina (Micropogonias furnieri). Ciência e Tecnologia de Alimentos, v.27, n.3, p.544-552, 2007. FAO - Food and Agriculture Organization of the United Nations. The State of World Fisheries and Aquaculture 2018. FAO: Rome, 2018.

FIGUEIREDO, S. M.; SIMÕES, L. R. C.; HOMEM, A. P. P.; PAULO, L. P.; SILVA, M. M. P.; SOARES, C. S; FARIAS, S. M. Oficina de Culinária: saberes e sabores do alimento. Scientia, v.3, n.1, p.39-48, 2010.

FREIRE, P. Pedagogia do oprimido. 50 ed. rev. e atual. Rio de Janeiro: Paz e Terra, 2011. FREIRE, P. C. M.; MANCINI-FILHO, J; FERREIRA, A. P. C. Principais alterações físicoquímicas em óleos e gorduras submetidos ao processo de fritura por imersão: regulamentação e efeitos na saúde. Revista de Nutrição, v.26, n.3, p.353-368, 2013. 
FRANÇA, N. A. G; MARTINI, L. A. Funções plenamente reconhecidas de nutrientes: cálcio. ILSI Brasil- International Life Sciences Institute do Brasil, v.2, n.1, p.3-23, 2014.

KIYA, M. C. S.; DIONIZIO, F. A. Q. Os desafios da escola pública paranaense na perspectiva do professor PDE. Curitiba: SEED, 2014. 45p.

LANES, D. V. C.; SANTOS, M. E. T.; SILVA, E. F. S. J.; LANES, K. G.; PUNTEL, R. L; FOLMER, V. Estratégias lúdicas para a construção de hábitos alimentares saudáveis na educação infantil. Revista Ciências \& Ideias, v.4, n.1, p.1-12, 2012.

LATORRES, J. M. Utilização de pescado na elaboração de produto destinado à merenda escolar. 214. 107 f. Dissertação (Mestrado de Engenharia de Alimentos), Universidade Federal do Rio Grande, Rio Grande do Sul, 2014.

MARTINS, M. B.; SUAIDEN, A. S.; PIOTTO, R. F; BARBOSA, M. Propriedades dos ácidos graxos poliinsaturados - Ômega 3 obtidos de óleo de peixe e óleo de linhaça. Revista do Instituto de Ciência da Saúde, v.26, n.2, p.153-156, 2008.

OLIVEIRA, C. M; DIAS, A. F. A criança e a importância do lúdico na educação. Revista Científica Multidisciplinar Núcleo do Conhecimento, v.13, n.1, p.113-128, 2017.

PEREIRA, R. C.; FERREIRA, L. O. C.; DINIZ, A. S.; BATISTA, M. F; FIGUEIRÔA, J. N. Eficácia da suplementação de ferro associado ou não à vitamina $A$ no controle da anemia em escolares. Cadernos de Saúde Pública, v.23, n.6, p.1415-1421, 2017.

PIRES, C. R. F.; SOUSA, D. N.; KATO, H. C. A.; SANTOS, V. F. Metodologias aplicadas na Educação alimentar e Nutricional para o aumento do consumo de pescado na alimentação escolar: relatos de experiências. Palmas: Editora UFT, 2020. 79p.

RIBEIRO, R. C.; BARROS, L. A.; PIRES, C. R. F.; KATO, H. C. A; SOUSA, D. N.

Avaliação do consumo de peixes no município de Palmas-TO. Indústria Animal, v.75, p.1$11,2018$.

SANTOS, A. N; SANTOS, A. N. O teatro e suas contribuições para a educação infantil na escola pública. Anais do ENDIPE - Encontro Nacional de Didática e Práticas de Ensino, Campinas, 16. Campinas, Unicamp, 2012.

SANTOS, V. F; PIRES, C. R. F; SOUSA, D. N; KATO, H. C. A. Metodologias lúdicas e educação alimentar e nutricional para promover o consumo de pescado em escolares. Revista de Extensão, v.16, p.126-142, 2019.

SCHERR, C.; GAGLIARD, A. C. M.; MINAME, M. H; SANTOS, R. D. Concentração de ácidos graxos e colesterol de peixes habitualmente consumidos no Brasil. Arquivos Brasileiros de Cardiologia, v.104, n.2, p.152-158, 2014.

SILVA, C. F. M.; PINTO, M. S.; PIRES, C. R. F; KATO, H. C. Relato de experiência de educação nutricional para o incentivo do consumo do pescado entre escolares do ensino 
fundamental em Palmas, Tocantins. Revista Em Extensão, v.16, n.1, p.140-149, 2017.

SILVA, M. X.; ALMEIDA, D. F.; RUIZ, A. S.; SOARES, B.; ALMEIDA, F.; SILVA J. X. S.; PEDROSA, C. Nutrição escolar consciente: oficinas de culinária para alunos do ensino fundamental das escolas públicas do município de Duque de Caxias/RJ.

Disponível em <https://bit.ly/3m5HHIA.> Acesso em 10 jan. 2020.

TEIXEIRA, L. O; REIS, I. H. K; SANTOS, V. F; PIRES, C. R. F; SOUSA, D. N; KATO, H. C. A. Relato de experiência de oficinas em Educação Alimentar e Nutricional: capacitação de merendeiras para a promoção da alimentação saudável em escolas. Revista Conexão Uepg, v.16, n.1, p.1-12, 2020. 